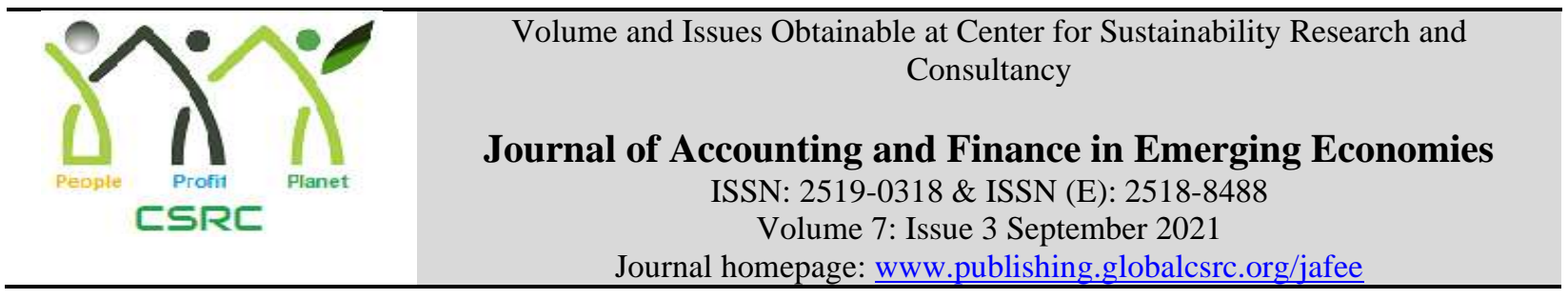

\title{
An Exploratory Inquiry into the Psychological Biases in Financial Investment Behavior Evidence from Pakistani Financial Markets
}

\author{
*Hussain Khawaja, Shaheed Zulfikar Ali Bhutto Institute of Science and Technology, \\ Hyderabad, Pakistan \\ Jameel Ahmed Khan, Shaheed Zulfikar Ali Bhutto Institute of Science and Technology, \\ Larkhana, Pakistan \\ Noor Mohammad Jamali, Shaheed Zulfikar Ali Bhutto Institute of Science and Technology, \\ Hyderabad, Pakistan
}

*Corresponding author's email: Hussain.khawaja@hyd.szabist.edu.pk

\begin{tabular}{l}
\hline ARTICLE DETAILS \\
\hline History \\
Revised format: Aug 2021 \\
Available Online: Sep 2021 \\
\hline Keywords \\
Psychological Biases, \\
Market Capitalization, \\
Mental Accounting, \\
Cognitive Dissonance. \\
\hline JEL Classification \\
G2, G1, M40, D91
\end{tabular}
\begin{abstract}
Purpose: This research aims to explore the psychological biases in the investment behavior of Pakistani investors, which refers to the natural inclination of investors towards specific financial products based on certain perceptions developed through information or news relating to the issuer of financial products Design/Methodology/Approach: A sample of twelve actively participating investors were selected in this research contacted through telephone in which the conversations were tape-recorded with the consent of the interviewee. It was then transcribed and coded into Ms. Word, or themes were developed.
\end{abstract}

Findings: Thematic analysis was conducted over the responses received; the results suggest that due to lack of training, knowledge relating to an investment in financial products, the behavior of investors is highly biased; partly either because of their association in the form of employment with issuing authorities or because of the news or information floated relating to financial products of the various companies.

Implications/Originality/Value: The study has many practical implications; the financial managers and consultants can design financial management behavior practical learning approach to reduce biases. Also, stock stockbrokers, investors identify such biases and reduce their impact. Furthermore, this study highlights the philosophical paradigm through ontological and epistemological understanding.

(C) 2021, The authors, under a Creative Commons AttributionNonCommercial 4.0

Recommended citation: Khawaja, H., Khan, J. A. and Jamali, N. M. (2021). An Exploratory Inquiry into the Psychological Biases in Financial Investment Behavior Evidence from Pakistani Financial Markets. Journal of Accounting and Finance in Emerging Economies, 7 (3), 739-748. 


\section{Introduction}

Financial Investment behavior is comprehensive decision-making influenced by a variety of factors. Individuals behave differently when making financial decisions. There are decisions based on personal judgment, whereas other decisions are made on many different factors. These financial decision-making processes become easier when different varieties are well understood by the decision-maker. Similarly, these decisions become difficult when financial complexity, i.e., risk, ambiguity, and choice overload, can seriously affect the household earning outcome. (Awais et al., 2016). Household financial management practice may be categorized as cash flow management, debt management, and investment management. (Hilgert et al., 2003) To understand this from the context of business enterprise is to examine the relation of designing a product according to the need of the household. The contemporary financial market offer variety of different financial products. This aids more to the wards complexity of decision making. (Diliberto [2006].

For an investor, effective decisions relating to commercial economics sources steer towards achieving desired results and to progress towards economic upliftment. (OECD 2004). Financial satisfaction refers to an increase he economic well-being-and hence an essential determinant of the future course of action(Vera-Toscano et al., 2006). In Pakistan, particularly Karachi Financial market in the given circumstances coupled with enormous complexity with the high number of companies in the markets offering numerous shares alternatives abound; getting insights into how investor responds to that situation when the actual decision-makers are inquired is particularly important, particularly in the role of investor biases. Previous studies have focused on the factor that affects investors' decision apropos financial decision. However, no attempt is made to understand the phenomena from the perspective of companies offering companies. This is because investment decisions have become complex, and therefore this research will help financial product companies determine different biases to take into account while offering their products is an essential part of a household's financial management practice (Diliberto [2006], Mudholkar and Sadique [2007]), understanding it in context of a business enterprise is a significant feature to design products accordingly; with the increasing competition in financial markets and new products being introduced every day makes this worthwhile (OECD 2004), for an investor, decisions regarding economic stability and enhancement of portfolio marks the notions of increased economic benefit. Nevertheless, massive transition and complexity in financial markets in introducing financial products has considerably increased over the years leading to heuristics and biases in financial investment behavior (Sjoberg and Engelberg [2006], Lovric, Kaymak and Spronk [2008]). Consequently, in the given circumstances coupled with enormous complexity with multiple actors in the marketplaces posing various asset substitutes abound; getting insights into how investor responds to that situation when the actual decision-makers are inquired is particularly important, particularly in the act of shareholder prejudices (Olsen [2007Pompeianian [2008]).

\section{Problem Statement}

In Pakistan, there are many financial products offered, which aids in the complexity of decisionmaking. Many factors affect the decision-making making of investors. Therefore, we are trying to explore the psychological bias that affects risk-taking taking ability and decision-making. The biases also led as beliefs and preferences act as lenses in the decision-making thought process hence; these biases and preferences could better be studied when real-time active investors are inquired on their beliefs and preferences.

\section{Objectives}

There are different reasons why an individual makes a particular decision regarding the financial investment. These decisions then impact the future outlook of the invite statement portfolio. How do they make these decisions regarding financial investment is the question? What beliefs and attitudes help make these decisions? The study investigates the biases that help those decisions and 
whether these biases are flaws or some design of investor's mind. This research is unique in its methodological and findings point of view as no previous research has been conducted on the biases of decision-making of financial investors in Pakistan.

\section{Literature Review}

Households 'Old's welfare rest on the quality of their financial decision-making. These financial decisions serve as the achieving landmarks or despairing individual welfare. Recent research indicates that individual strives to make the most of their financial decision by improving their portfolio by reducing risk. (Hilgert et al., 2003) There are many financial theories, for example, Modern Portfolio Theory, Capital Asset Pricing Model, Efficient Market Hypothesis, that describes the financialial management behavior of an individual.

Nevertheless, the thing in the market does not usually follow financial theories. The individuals, while making a decision, depends a lot on irrational investment behavior. These attitudes disregard the rational approach and therefore are considered biases in decision making. These attitudes are part of an individual, and more often than not, the investor does not even know apropos to these biases and therefore fail to overcome these behavior which results in inappropriate decision making.(Kubilay \& Bayrakdaroglu, 2016) Thus effective financial decision-making requires e knowledge-based approach and reduction biases.

\section{Different Psychological biases Rule of Thumb (heuristics)}

Heuristics is basically the rule of thumb, which explains how investors make a decision during uncertain situations based on emotional and mental factors along with a trial-and-error basis. This way, investors usually gather information related to the situation; however, they make decisions based on their judgment, which is far from rational decision-making and can lead to poor results.(Kubilay \& Bayrakdaroglu, 2016)

\section{Representative Bias}

The investor looks for the similarity of the cases solved in the past. Alternatively, the decisionmaking that has come through in the past. The investor looks for similar qualities of shares. The investor makes a decision based on past successful decisions. (Marchand, 2012)

\section{Overconfidence Bias}

The investors may not be trained or skilled enough, though they make decisions based on their ability to estimate information. They overemphasize their ability to make the decision based on what they believe know is enough to make a suitable decision. Investors may believe that they have more skills than other average investors. The tendency to believe that they know more than they actually know. (Marchand, 2012)

\section{Anchoring Bias}

The ability of an individual to rely on a single trait or a piece of information while deciding is called anchoring bias. For example, some people may react to the initial information and base their forecast on it.(Kubilay \& Bayrakdaroglu, 2016)

\section{Availability Bias}

The investor rests their decision based on the information most readily available. Unfortunately, this approach lacks the critical analysis of the situation and can lead to adverse results.(Kubilay \& Bayrakdaroglu, 2016) 


\section{Prospect Theory}

The prospect theory was initially proposed by Kahneman and Tversky (1979). This theory purports that there are two different phases in any choice. One is evaluation, and the other is framing. The Prospect theory was initially advocated by Kahneman and Tversky (1979) and advanced by Daniel Kahneman, which crowned him with Noble laureate in the discipline of Economics. The concept put forward segregates the decision process into phases: The initial phase is demarcated as framing and the succeeding stage of evaluation. (Kubilay \& Bayrakdaroglu, 2016) The theory explains that investors have diverse approaches in coping with risk and uncertainty. The investor does not avoid risk in a difficult situation. However, they avoid risk while earning a good return. This is also called the risk aversion concept, in which the financial decision-maker is more inclined towards risk when faces losses and is more prone to risk-averse when there is a chance of a gain. (Kubilay \& Bayrakdaroglu, 2016) The regret aversion is another essential psychological phenomenon that exerts that people make mistakes in their financial investment management, the undesirable emotion that arises after these choices restrict them from making other choices. As a result, they try to hold loss-making shares and try to sell gain-producing shares immediately. Investors do not want to be in negative feelings for a very long time, and therefore they adjust their emotions by selling the profitable share to ward off negative feelings.

Cognitive dissonance discusses the two inconsistent views that the person holds. This yields distress in the investor's mind, so they try to reduce one of these views by modifying one of their attitudes. For example, when avoiding the feeling of pain, they try to convince themselves apropos rationality of their decision.

The mental accounting is another psychological bias that exerts that investor attach different values using cognitive skills. The way they will spend it depend on it is subject to inconsistent mind operation without following any economic guidelines. Because of such an attitude, investors fail to embark on the opportunities while designating money for preconceived investment. The irrational decision-making behavior may end up spending more and saving less for future opportunities.

Self-control is another psychological behavior that investors follow when they are unable to plan for the future by investing too much today. As a result, investors may inaccurately spend without realizing the asset imbalance. (Kubilay \& Bayrakdaroglu, 2016)

\section{Philosophical Underpinning}

Till the $19^{\text {th }}$ century, only one method was assumed as an objective reasoning research methodology. At the beginning of the $20^{\text {th }}$ century, another saw a new research method evolve, i.e., Qualitative research methodology. This methodology emphasizes the construction of the social reality and thus can also be justified as an objective research method. (Soiferman, L.K., 2010). The qualitative method justifies that reality can be gained through multiple sources, not just from scientific facts, as observed in quantitative research. In the qualitative method, the bonding of the observer with the object signifies the fact. The ontology of qualitative research is the subjective lens to view the reality. (Simon, 2011). The qualitative research follows interpretative research philosophy, which undermines that reality is interpreted from the data collected. The types of methodological grounds established depend more on the question the research is trying to answer. The researcher gathers the data by observing or interviewing the participants in the natural setting, converting data into meaningful themes, and then developing theories inductively. (Janosik, 2005)

\section{Themes}

Market Capitalization (Historical data, index points, buying power, market sentiments) 
Diversification (preferable investment)

Riskiness (risk-averse, risk-taker, volatility, growth and defensive strategy, holding back for opportunities, financial indicators, luck, no benchmark, random selection)

Experience in the same field (personal experience in the field, familiar products, and favorable sectors)

\section{Market Capitalization}

The theme entails the total capital invested by any investor in the capital market; the majority of respondents in the research believe that the whole of the investment that an individual decisionmaker brings to the market is based on the certain expectations associated with it, this includes the amount of capital initiated by the investor, total points that a particular stock increases or decreases in any single day, the buying power of the investor, and lastly the market sentiments- the word of mouth or the perception created in the minds of overall investors, altogether, these elements relating to the investment behavior are highly associated with these factors, if these factors portray positive incentives there are chances that an investor will definitely invest his/ her savings in that financial product.

\section{Diversification}

This theme of the research entails the spread of the total investment across various securities or financial products; the respondents highly perceive that any investment diversified across multiple securities or financial products will tend to bring large amounts of profits, and this diversification accordingly modifies the investment behaviors of investors willing to put forth their savings into different financial products.

\section{Riskiness}

The transcript of interviews clearly indicate that the investment in financial products is highly uncertain and that there are behaviors that need to be understood by the investors, for example, risk-taking and avoiding risks are both two opposite sides of one aspect, an investor tends to think as a broad rather than sticking to his/ her safe zone, there are circumstances when you have to invest your entire savings and come up to know that investments should have been placed at a better place, or before investing your money, one should make sure that the money invested is in a portfolio that has the ability to brings good profits back in hands, so this theme containing the riskiness behaviors should be taken into account very seriously.

\section{Experience}

This theme entails one's association with any company; as per the interviews by the researcher, it would be noted that majority of respondents were of the views that they usually opt for financial products which are highly familiar or that some basic knowledge of the issuing authority, this indicates that the respondents were not aware of the other techniques or options available for them to invest in stocks or financial products which are more potential products that might be more profitable for the investors than the existing portfolio of investments.

\section{Research Methodology \\ Research Design}

We have embarked on exploratory qualitative research, which consists of taking interviews from a financially active shareholder of Karachi. These participants buy and sell shares on a daily basis and therefore were considered crucial in our study. Because of the pandemic, Hussain Khawaja and Jameel Ahmed Khan conducted a telephonic interview. A qualitative thematic analysis study was assumed to be most appropriate as we wanted to explore in-depth information and analyze the impact of different biases in the decision-making process. Ethics approval was taken from the Institute of Business Management. 


\section{Sampling and Recruitment}

The sampling of data was based on purposive sampling. This is due to the fact that we needed the data from investors who are frequently investing Karachi Stock Exchange. This provided us with a wide range of raw data from different investment behavior. The Table shows how the participants of the interview shaped. The entire information providers (interviewees) in this study participated voluntarily. The interview participants were given an invitation to participate in an interview. This also consists of an information leaflet and interview guide. The data was gathered until we attained data saturation.

Table 1: Respondents Information

\begin{tabular}{|c|c|c|c|c|}
\hline Interview & Gender & occupation & Location & status \\
\hline 1 & Male & Investor & Karachi & Active Investor \\
\hline 2 & Female & $\begin{array}{c}\text { Internal } \\
\text { Auditor }\end{array}$ & Karachi & Active Investor \\
\hline 3 & Male & Doctor & Karachi & Active Investor \\
\hline 4 & Male & Investor & Karachi & Active Investor \\
\hline 5 & Male & $\begin{array}{c}\text { Real Estate } \\
\text { Agent }\end{array}$ & Karachi & Active Investor \\
\hline 6 & Female & Private Job & Karachi & Active Investor \\
\hline 7 & Male & Private Job & Karachi & Active Investor \\
\hline 8 & Male & Government & Karachi & Active Investor \\
\hline 9 & Male & Investor & Karachi & Active Investor \\
\hline 10 & Male & Investor & Karachi & Active Investor \\
\hline 11 & Male & Investor & Karachi & Active Investor \\
\hline 12 & Male & Teacher & Karachi & Active Investor \\
\hline
\end{tabular}

\section{Data Generation}

The average duration of the interview was 27 minutes. The most extended interview lasted for 35 minutes, and the shortest interview was 22 minutes. The interviews were conducted from $10^{\text {th }}$ August 2020 to $20^{\text {th }}$ August 2020. Interviews were conducted in Urdu and English according to the interviewee's preference. The interviewee was verbally informed before the interview regarding the intention to conduct the interview, and verbal consent was also taken. The interviews were initiated with a topic guide. However, participants were given complete freedom the put forward their views.

\section{Data handling and Analysis}

The data gathered through interviews were tape-recorded and then were transcribed by Jameel Ahmed khan and Hussain Khawaja. The transcripts of the raw interview were gathered on MS word document. The iterating analysis was undertaken in order to obtain codes and themes. The analysis was also encouraged to obtain any extreme case into the account. We analyzed the data vigilantly without drawing any interview bias into the study. The data was analyzed using Nvivo software.

\section{Method of Reasoning}

The inductive reasoning is defined as a type of research that moves from experience and observation to developing themes to constructing a theory. In other words, the inductive reasoning approach moves from specific to general. (Soiferman, L.K., 2010). In this study, the data is collected from individual investors to gain an understanding of the biases of their investment behavior. 


\section{The Rigorousness of Research}

The qualitative method is criticized for lack of scientific measurement that outlines the credibility of the data. (Nowell et al., 2017) state that there are a number of ways to achieve the credibility of qualitative thematic analysis research; one such method is Member Checking. In this study, we confirmed the finding of the raw data with all the respondents in order to test the interpretation is achieved in accordance with the respondent utterance.

\section{Transferability}

Transferability refers to the generalizability of the finding. (Nowell et al., 2017) This study provides a detailed account of active investor biases and how financial investors can improve decision-making in the natural setting.

Table 2: Responses Coded

\begin{tabular}{|c|c|c|c|c|}
\hline & $\begin{array}{c}\text { A: Diversified } \\
\text { Investments }\end{array}$ & B: Experience & $\begin{array}{c}\text { C: Market } \\
\text { capitalization }\end{array}$ & $\begin{array}{c}\text { D : } \\
\text { Risk behavior }\end{array}$ \\
\hline 1: Interview 02 & 1 & 1 & 5 & 1 \\
\hline 2: Interview 03 & 2 & 4 & 6 & 1 \\
\hline 3: Interview 04 & 1 & 5 & 5 & 1 \\
\hline 4: Interview 05 & 0 & 3 & 6 & 1 \\
\hline 5: Interview 06 & 1 & 3 & 3 & 1 \\
\hline 6: Interview 10 & 1 & 2 & 3 & 1 \\
\hline 7: Interview 11 & 2 & 2 & 2 & 1 \\
\hline 8: Interview 12 & 1 & 2 & 4 & 2 \\
\hline 9: Interview 7 & 1 & 3 & 6 & 1 \\
\hline 10: Interview 8 & 0 & 2 & 3 & 1 \\
\hline 11: Interview 9 & 1 & 4 & & 3 \\
\hline 12: Interview 1 & 1 & & 3 & 3 \\
\hline
\end{tabular}


Table 3: Mind Mapping

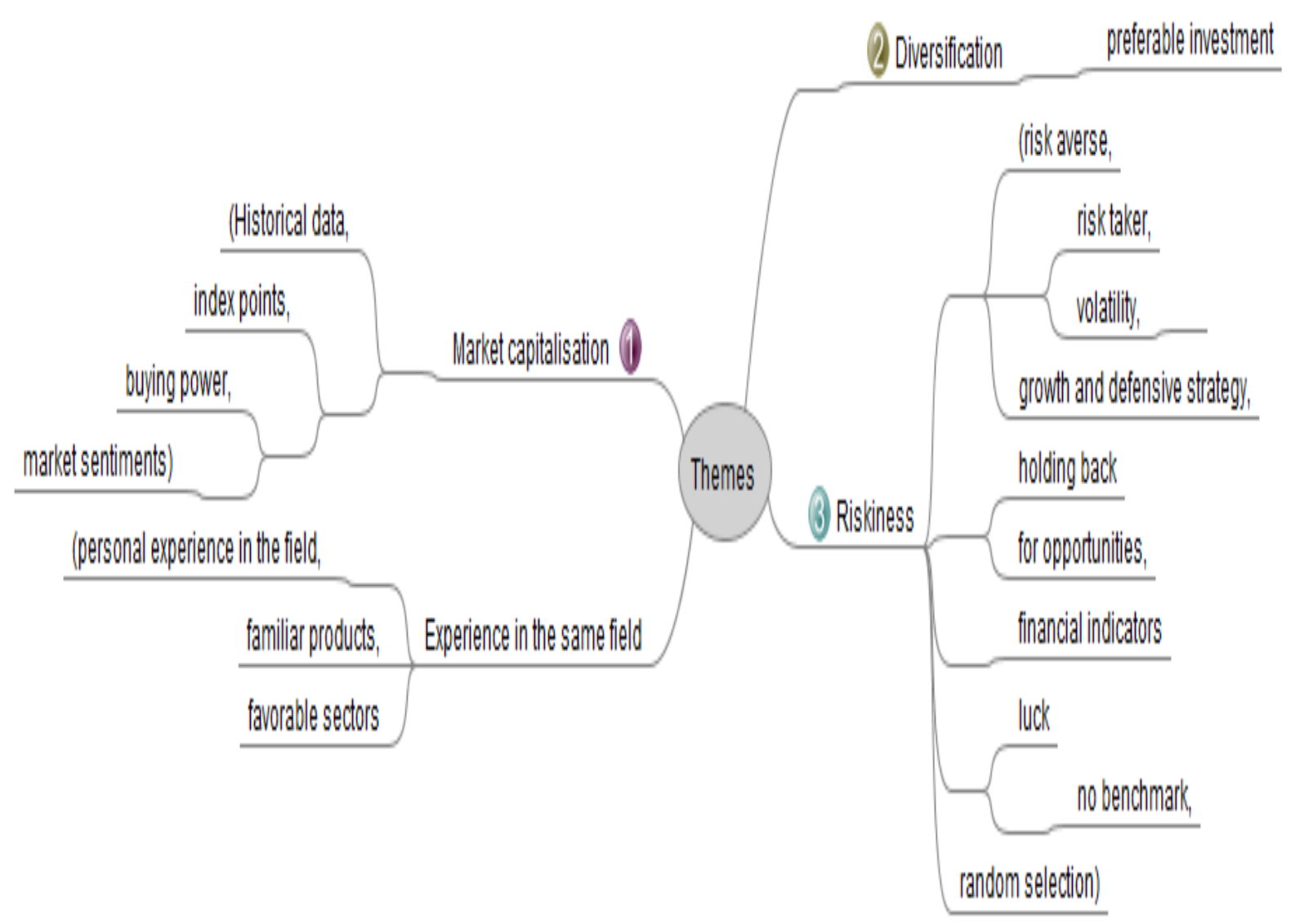

\section{Results and Discussions}

This research aims to study the psychological biases in investment behavior in the context of Pakistani investors. These psychological biases mean the general tendency of an investor towards any financial product of a company, he or she has own preferences and attitudes towards a financial product that influences and alters the actual investment behavior, by following the rigorous process of conducting interviews from the selected respondents from Pakistan Stock Exchange duly registered with brokerage houses, we conclude that the investors in Pakistani context are heavily going through some biases, which significantly affect their investment behaviors.

Firstly, there is a specific set of assumptions that an investor considers before making an investment in any financial product; these assumptions vary according to their professional and social circle, assumptions include such as country's political or economic conditions shall remain same so does the volatility of prices of financial products, which subsequently creates hope for the investors that this volatility in the prices acts as a way to maximize profits for investors, an employee working in Oil and Gas sector also an active investor of stock market develops such expectations accordingly as there is an energy crisis in the country and this has remained a trend in the country that the prices of commodities shall always fluctuate, similarly a banking employee has similar sort of expectations due to access to the financial system of the country. Another assumption includes that the world agrees on the fact that the stock markets are always manipulated and that some big guns of the country strongly influence the way it has to operate, for example, if people from bureaucracy 
has invested their savings into the sector of their choices, they can affect the way market operate in the context of that sector. Investors have similar sort of perceptions/assumptions related to the Pakistan Stock Market as well. Considering these assumptions, their behavior related to any financial product is affected accordingly. From the literature point of view, the investors in the Pakistani Stock Exchange are incredibly biased in terms of their ability to trade in the stock market, which requires at least basic knowledge to trade financial products of listed companies. The literature supports our findings and endorses that the investors in Pakistani markets are biased in these two following categories.

\section{Heuristics Biases}

Since an investor always perceives that the market is highly uncertain and the history confirms this notion, therefore, an investor, without going or referring to the fundamentals of any sector or company, invests his or her money in the stock market in a time which he/she considers as the uncertain time and anything is possible, with the expectation of appreciation in the price of a stock, since he/she is a working employee of any company in which the same individual has invested money, considering the inside information might change his or her Destiney.

\section{Overconfidence Biases}

As per our observation from the selected respondents, the majority of the respondents lack training when it comes to trading financial securities in Pakistan; without the basics of any company, an investor creates a notion into his or her mind expecting that the investment put forth will always bring positive returns to him. This way, the investors are also the victims of overconfidence biases, considering their level of knowledge is enough to understand the game behind the trading mechanism in the stock market.

\section{Conclusion}

This research investigation concludes on the findings that the investment behavior of investors should genuinely be based on merit of the financial products rather than other factors relating to the perception of investors which develops from time to time, considering the market for financial products in Pakistan, investors in Pakistani stock market are not that much trained to actively invest in the financial products, investment in financial products requires the initial fundamental and technical analysis which at least requires the basic understandings of financial terms so that an investor actively investing in financial products of any company might initially goes some basics to understand the market sentiments of financial products but here; majority of the investors belong to a class that has no basic education; who actively invest in the stock market, our sample we considered were individuals from different spheres of life including medical and engineering background, for these respondents, investment in financial products is highly biased, as per the responses deducted from thematic analysis, there are investors in Pakistani market who never consider any training neither any consultancy from specialized experts, therefore; investment behaviors in context of Pakistani investors investing in financial products is entirely different from those of others.

The primary kind of biases that people are going through in the Pakistani context are heuristics and overconfidence biases; both types of biases suggested by the literature is strongly observed in the case of Pakistani investors, which ultimately shows the lack of awareness amongst the Pakistani investors. 


\section{References}

Alfred, Lord Tennyson Bias, S. (1880). Self-Control Bias. 211-222

Awais, M., Fahad Laber, M., Rasheed, N., \& Khursheed, A. (2016). Impact of financial literacy and investment experience on risk tolerance and investment decisions: Empirical evidence from Pakistan. International Journal of Economics and Financial Issues, 6(1), 73-79.

Bias, R. A. (2015). Regret Aversion Bias. Behavioral Finance and Wealth Management, 243-251. https://doi.org/10.1002/9781119202400.ch22

Duclos, R. (2014). The psychology of investment behavior: (De)biasing financial decision-making one graph at a time. Journal of Consumer Psychology, 25(2), 317-325. https://doi.org/10.1016/j.jcps.2014.11.005

Hilgert, M., Hogarth, J., \& Beverly, S. (2003). Household financial management: the connection between knowledge and behavior. Federal Reserve Bulletin, 106(Jul), 309-322.

Khresna Brahmana, R., Hooy, C., \& Ahmad, Z. (2012). Psychological factors on irrational financial decision making: Case of the day $\square$ of $\square$ the week anomaly. Humanomics, 28(4), 236-257. https://doi.org/10.1108/08288661211277317

Kubilay, B., \& Bayrakdaroglu, A. (2016). An Empirical Research on Investor Biases in Financial Decision-Making, Financial Risk Tolerance, and Financial Personality. International Journal of Financial Research, 7(2), 171-182. https://doi.org/10.5430/ijfr.v7n2p171

Madaan, G., \& Singh, S. (2019). An analysis of behavioral biases in investment decision-making. International Journal of Financial Research, 10(4), 55-67. https://doi.org/10.5430/ijfr.v10n4p55

Marchand, M. (2012). Behavioral biases in financial decision-making. 8200, 1-28.

Mühl, J. K. (2014). Research methodology. Contributions to Management Science, 75-100. https://doi.org/10.1007/978-3-319-04069-1_4

N, S. (2015). Heuristic and Biases Related To Financial Investment and the Role of Behavioral Finance in Investment Decisions - a Study. ZENITH International Journal of Business Economics \& Management Research, 5(12), 82-101. https://doi.org/10.1108/01443570310501907

N, S. (2015). Heuristic and Biases Related To Financial Investment and the Role of Behavioral Finance in Investment Decisions - a Study. ZENITH International Journal of Business Economics \& Management Research, 5(12), 82-101. https://doi.org/10.1108/01443570310501907

Nowell, L. S., Norris, J. M., White, D. E., \& Moules, N. J. (2017). Thematic Analysis: Striving to Meet the Trustworthiness Criteria. International Journal of Qualitative Methods, 16(1), 113. https://doi.org/10.1177/1609406917733847

Sahi, S. K., Arora, A. P., \& Dhameja, N. (2013). An Exploratory Inquiry into the Psychological Biases in Financial Investment Behavior. Journal of Behavioral Finance, 14(2), 94-103. https://doi.org/10.1080/15427560.2013.790387

Simon, M. K. (2011). Assumptions, limitations, and delimitations. http://dissertationrecipes.com/wpcontent/uploads/2011/04/AssumptionslimitationsdelimitationsX.pdf

Sindhu, A. (2012). Chapter 2 : Research Methodology Chapter 2 : Research Methodology. 6-16. https://repository.up.ac.za/bitstream/handle/2263/24260/02chapter2.pdf?sequence $=3$

Soiferman, L.K. (2010). Inductive and Deductive Research Approaches. April 1-23.

Subhani, M. S., Khan, R. A. and Sultan, K. (2021). Pakistani Newspaper on Peace Talks with Tahrik e Taliban Pakistan. Journal of Accounting and Finance in Emerging Economies, 1 (1) $47-60$

Thomas A. Schwandt. (1998). Schwandt.pdf (p. 189).

Vera-Toscano, E., Ateca-Amestoy, V., \& Serrano-del-Rosal, R. (2006). Building financial satisfaction. Social Indicators Research, 77(2), 211-243. https://doi.org/10.1007/s11205005-2614-3. 